\title{
The Benefits of the $\mathrm{ZnO} / \mathrm{Clay}$ Composite Formation as a Promising Antifungal Coating for Paint Applications
}

\author{
Eva de Lucas-Gil ${ }^{1}$, Javier Menéndez ${ }^{2}$, Laura Pascual ${ }^{3}$, José F. Fernández ${ }^{1} \mathbb{D}$ and \\ Fernando Rubio-Marcos 1,4,*iD \\ 1 Electroceramic Department, Instituto de Cerámica y Vidrio, CSIC, Kelsen 5, 28049 Madrid, Spain; \\ elucas@icv.csic.es (E.d.L.-G.); jfernandez@icv.csic.es (J.F.F.) \\ 2 Encapsulae, S.L., Lituania, 10, 12006 Castellón de la Plana, Spain; jmenendez@asepticae.com \\ 3 Instituto de Catálisis y Petroleoquímica, CSIC, Marie Curie 2, 28049 Madrid, Spain; laura.pascual@icp.csic.es \\ 4 Escuela Politécnica Superior. Universidad Antonio de Nebrija. C/Pirineos, 55, 28040 Madrid, Spain \\ * Correspondence: frmarcos@icv.csic.es
}

Received: 23 January 2020; Accepted: 11 February 2020; Published: 15 February 2020

Featured Application: Herein, we provide an inorganic composite as a paint preservative for antifungal applications. From a paint commercial additive, we add synthesized $\mathrm{ZnO}$ nanoparticles in order to improve the antimicrobial response. The main aim of this study is to generate a cost-efficient, eco-friendly material, without human health risk. We have developed a method for the controlled dispersion of $\mathrm{ZnO}$ nanoparticles on paint additive through a cooperative assembly-directed process at room temperature. The antifungal response of the inorganic composite is tested against the common fungi, Aspergillus niger. In this work we take a step further, studying the composite developed in a paint application. We believe that this paper can serve as a turning point in the search of alternative preservatives against fungi in different environments from industrial to hospital.

\begin{abstract}
The presence of mold is a serious problem in different environments as industrial, agricultural, hospital and household, especially for human health. Large quantities of mold spores can potentially cause allergic reactions and respiratory problems. Therefore, it is essential to keep buildings free of fungi without harming human health and the environment. Here, we pose a composite of modified bentonite clay and $\mathrm{ZnO}$ nanoparticles as an alternative antifungal preservative. The new composite is obtained by an easy and eco-friendly method based on a dry nanodispersion, without altering the properties of each material. The antifungal test reveals a robust response against fungi thanks to the $\mathrm{ZnO}$ nanoparticles' contribution. Our results reveal that the antifungal activity of $\mathrm{ZnO} /$ clay composite is governed by both a uniform distribution and an adequate concentration of the $\mathrm{ZnO}$ nanoparticles onto the clay surface. Specifically, we find that for concentration below $10 \mathrm{wt} . \%$ of the $\mathrm{ZnO}$ nanoparticles, the nanoparticles are well dispersed onto clay giving rise to an excellent antifungal response. By contrast, when the concentration of $\mathrm{ZnO}$ increases, the formation of $\mathrm{ZnO}$ agglomerates onto the clay surface is favored. This effect provokes that antifungal behavior changes towards a more moderate improvement. Finally, we have demonstrated that this composite can be used as a promising paint preservative for antifungal applications.
\end{abstract}

Keywords: $\mathrm{ZnO}$; modified clay; coating; antifungal response

\section{Introduction}

Fungicide use is extensive in different environments such as industrial, agricultural, hospital and household. Its applications range from the protection of seed grain during storage, suppression of 
mildews that attack painted surfaces, control of slime in paper pulps to the protection of carpet and fabrics in the home, among others [1]. So important is fungicide use that ca. 500 million pounds of fungicides are applied worldwide annually [1]. The term fungicide refers to either chemicals or biological agents that inhibit the growth of fungi or fungal spores [2]. Over time, numerous substances employed as fungicides have a wide and diverse chemical structural spectrum, covering both inorganic and organic substances [3]. Some of the earliest fungicides were inorganic materials such as sulfur, lime, copper and mercury compounds [4]. However, many countries have been withdrawn some of the inorganic metallic fungicides, especially mercurous compounds, due to their high toxicity and adverse environmental effects [3]. This fact does not only focus on inorganic fungicides but also organic fungicides are under review. For example, vinclozolin has been removed from use for damage to human health and several fungicides are known to cause developmental toxicity and oncogenesis $[2,4]$. Today, the main role of modern fungicides is the inhibition of fungi growth and/or fungal spores (i.e., they do not kill fungi). To reduce the toxicity of fungicides, the new routes consist of finding alternatives from natural resources. When the term fungus is defined, several classes are included as yeast, mold, and fungi. In a household environment, the presence of mold is a serious problem. Large quantities of mold spores can be a risk to the health of humans, potentially causing allergic reactions and respiratory problems. Therefore, it is essential to keep buildings, like houses or hospitals, free of microorganisms, such as fungi and even bacteria, with antimicrobial agents that show low-toxicity for humans.

Zinc pyrithione $(\mathrm{ZnPT})$ is a broad-spectrum antimicrobial agent that works against the growth of bacteria, fungi, and mold. This agent is registered in the Food and Drug Administration (FDA) because of numerous applications, such as medical, scientific and industrial. The main applications of $\mathrm{ZnPT}$ are as a fungicide in anti-dandruff shampoos, anti-fouling agents for boats [5], or it is also included in textiles [6], adhesives, paints [7], etc. Despite the antimicrobial advantages of ZnPT, there are doubts about its potential toxicity. ZnPT shows high toxicity to aquatic plants and animals such as algae, invertebrates, crustaceans, and fishes [8,9]. Likewise, some studies report the potential penetration of $\mathrm{ZnPT}$ in human epidermis, causing cell damage $[10,11]$. European Union carries out periodic reviews about the recommended concentrations of ZnPT not to be harmful to human health [7]. Therefore, there is no clear certainty about the cytotoxicity absence of ZnPT. In addition, ZnPT can easily photodegrade via direct photolysis under solar irradiation [12]. This photochemical degradation of $\mathrm{ZnPT}$ can modify its properties and activity, not allowing antimicrobial effectiveness in areas exposed to light.

Given the background here mentioned, zinc oxide is posed as an antimicrobial agent alternative in agreement with the new idea of looking for materials from natural resources. Zinc is a bio element necessary for life in small quantities in living beings. The oxide form, $\mathrm{ZnO}$, is found in nature as the zincite mineral, although the vast majority of $\mathrm{ZnO}$ is produced synthetically. The antimicrobial response of $\mathrm{ZnO}$ is widely reported, both for bacteria and fungi [13-21]. Most researchers correlate the antimicrobial activity of $\mathrm{ZnO}$ with the particle size, being more effective in the nanometric scale [22-24]. More specifically for fungi, Lipovsky et al. [18] reported the improvement of the antifungal activity attributing it to the reduction in size and to the increase in the surface area to volume ratio. With respect to risk on human health, there is no definite evidence that $\mathrm{ZnO}$ nanoparticles pose a health hazard, instead of that they provide obvious health benefits [25]. These properties make $\mathrm{ZnO}$ a good candidate as a fungicide alternative. However, in a generic way, the nanoparticles' use is on suspicion due to the potential toxicity. The presence of nanoparticles is strictly regulated in areas such as cosmetics and food, where their use is restricted. Thus, we pose a deposition of $\mathrm{ZnO}$ nanoparticles in a matrix that acts as a support and as a vehicle.

Herein, we provide an inorganic composite as a paint preservative for antifungal applications. From a paint commercial additive, we add synthesized $\mathrm{ZnO}$ nanoparticles in order to improve the antimicrobial response. The main aim of this study is to generate a cost-efficient, eco-friendly material, without human health risk. We have developed a method for the controlled dispersion of $\mathrm{ZnO}$ nanoparticles on paint additive through a cooperative assembly-directed process at room 
temperature. The antifungal response of the inorganic composite is tested against the common fungi, Aspergillus niger. Thanks to excellent results, this composite can be used in a wide range of applications. Therefore, we go one step further on potential applications by testing the antifungal activity of $\mathrm{ZnO}$ composite in a waterborne paint matrix.

\section{Materials and Methods}

Size modification process of the micrometric $\mathrm{ZnO}$ via chemical route. All the chemicals were directly used without further purification. Micrometric $\mathrm{ZnO}$ (microZnO), used in the reaction, consists of hexagonal prisms with lengths of 1-2 $\mu \mathrm{m}$. First, $6 \mathrm{wt} . \%$ micrometric zinc oxide (ZnO, Asturiana de Cinc S.A., Arnao, AS, Spain) was added to $3.6 \mathrm{~mol}$ of glycerol (Sigma-Aldrich, Madrid, MAD, Spain) under stirring at room temperature. It should be highlighted that micrometric $\mathrm{ZnO}$ (microZnO), used in the reaction, consists of hexagonal prisms with lengths of 1-2 $\mu \mathrm{m}$, see Figure S1a,b (Supplementary Materials). When the suspension was homogenized, $3.6 \mathrm{~mol}$ of urea $\left(\mathrm{CO}\left(\mathrm{NH}_{2}\right)_{2}\right.$, Sigma-Aldrich, Madrid, MAD, Spain) was added. Subsequently, the reaction was heated in a silicone bath at $120-140^{\circ} \mathrm{C}$ for $2 \mathrm{~h}$ with continuous agitation at $300 \mathrm{rpm}$. The role of urea was to provide the reaction with ammonia and $\mathrm{CO}_{2}$, from its decomposition. The presence of ammonia generates a basic $\mathrm{pH}$ during the reaction. Under these conditions, the $\mathrm{Zn}$ species were reacted with $\mathrm{H}_{2} \mathrm{O}$ and high-pressurized $\mathrm{CO}_{2}$ to create a hydrozincite phase (see Figure S1b (Supplementary Materials)). It was demonstrated that the hydrozincite (that is, reaction intermediate product) contains a high proportion of porous distribution, which should be produced by its morphologies in form of nano-sheet. After naturally cooling, the precipitate was isolated by filtration and washed with water and ethanol several times to remove impurities. The white powder was dried at $80{ }^{\circ} \mathrm{C}$ for $24 \mathrm{~h}$. Finally, the product was thermally treated at $500{ }^{\circ} \mathrm{C}$ for a short time, $5 \mathrm{~min}$, in the air. Note that the heat treatment at $500{ }^{\circ} \mathrm{C}$ produces a new phase transformation from hydrozincite to $\mathrm{ZnO}$ (see Figures S1b,c and S2 (Supplementary Materials)), which is faster and further completes at a higher temperature of $400{ }^{\circ} \mathrm{C}$ [26]. Due to the morphology of the hydrozincite in the formof nano-sheets, the heat treatment at $500{ }^{\circ} \mathrm{C}$ generates the appearance of cracks in its structure, which are expanded leading to the formation of the $\mathrm{ZnO}$ nanoparticles in order to decrease the surface energy. The experimental details are schematically shown in Figure S1c (Supplementary Materials).

Formation Process of Inorganic Composites. The modified clay (Clay) was supplied by NanoBioMatters Industries S.L. (Paterna, VAL, Spain) The main composition of modified clay is bentonite clay $(68.1 \%-78.1 \%)$, modified with $20-30 \mathrm{wt} . \%$ of hexadecyltrimethylammonium bromide $\left(\mathrm{C}_{19} \mathrm{H}_{42} \mathrm{BrN}\right)$ and $1.9 \mathrm{wt} . \%$ of silver. The inorganic composite was obtained by the combination of modified clay ( $\mathrm{ZnO} / \mathrm{Clay}$ ) with a different percentage of $\mathrm{ZnO}$ (from 2 to $60 \mathrm{wt} . \%$ ) by using the dry dispersion methodology. The advantages of using dry dispersion are to ensure both the stability of the inorganic composite and the homogeneous distribution of $\mathrm{ZnO}$ in spite of the low dose.

Paint preparation. The selected paint was supplied by Xylazel S.A. (Madrid, MAD, Spain) The formulations of waterborne paint were treated with $0.5 \mathrm{wt} . \%$ of inorganic composite $\mathrm{ZnO} / \mathrm{Clay}$.

Characterization. Crystalline phases were characterized by X-ray diffraction (XRD, X'Pert PRO Theta/2theta of Panalytical, $\mathrm{Cu} K \alpha$ radiation, PANalytical, The Netherlands). The pattern was recorded over the angular range $20^{\circ}-70^{\circ}(2 \theta)$ with a step size of $0.0334^{\circ}$ and a time per step of $100 \mathrm{~s}$, using $\mathrm{Cu} \mathrm{K} \alpha$ radiation $(\lambda=0.154056 \mathrm{~nm})$, with a working voltage of $40 \mathrm{kV}$ and current of $100 \mathrm{~mA}$. The morphology of samples was evaluated using primary electrons images of field emission scanning electron microscopy (FE-SEM, Hitachi S-4700, Tokyo, Japan). An image processing and analysis program (Leica Qwin, Leica Microsystems Ltd., Cambridge, UK) were performed to determine the average particle size from FE-SEM micrographs. In addition, a detailed morphology and crystal structure of the sample was evaluated using a transmission electron microscope (TEM/STEM, JEOL 2100F, Tokyo, Japan) operating at $200 \mathrm{kV}$ and equipped with a field emission electron gun providing a point resolution of $0.19 \mathrm{~nm}$. For TEM sample preparation, the particles were carefully suspended in ethanol and dispersed using 
an ultra-sonication bath for $10 \mathrm{~min}$. The suspension was dropped on a lacey carbon copper TEM grid. After the evaporation of ethanol, the particles were kept at the grid.

Antifungal activity test. The pathogenic fungus selected for testing is Aspergillus niger (CECT 2807). Antifungal tests were performed by the Bauer-Kirby disk diffusion assay with some modifications. First, the culture of A. niger (initial concentration of $5.20 \times 107$ spores $/ \mathrm{mL}$ ) was inoculated on the surface of Petri dishes. After that, filter paper disks were impregnated with a suspension of $0.5 \%$ different inorganic composites $\mathrm{ZnO} /$ Clay. Then, the inoculated Petri dishes were incubated at $37^{\circ} \mathrm{C}$ for 7 days. The effectiveness of $\mathrm{ZnO} / \mathrm{Clay}$ samples was evaluated by measuring the inhibition diameter of the grown fungus in the Petri dish. For the paint antifungal activity, no filter paper disks were used. The paint was in direct contact with the fungi culture. Two kinds of the test were performed to know the antifungal activity of modified paint, one with fresh paint and another with dry paint. The dry paint was obtained after a $90^{\circ} \mathrm{C}$ thermal treatment for $24 \mathrm{~h}$. All tests were performed in triplicate and the values were expressed in millimeters.

\section{Results and Discussion}

\subsection{Initial Premises: High Antimicrobial Response of the Nanoparticulated $\mathrm{ZnO}$}

The particle size of the micrometric $\mathrm{ZnO}$ is modified by a chemical process and then, the obtained material is thermally treated at $500{ }^{\circ} \mathrm{C}$ for a short time, $5 \mathrm{~min}$, in the air. (The reader can find more information about the $\mathrm{ZnO}$ synthesis in the Material and Methods section) The obtained $\mathrm{ZnO}$ is structurally characterized by X-ray diffraction (XRD) and Fourier transform infrared spectroscopy (FTIR). The XRD pattern of obtained ZnO shows a single crystalline structure (Figure S2a (Supplementary Materials)). The position and intensity of the diffraction peaks match the hexagonal wurtzite structure ZnO (JCPDS Card No. 36-1451). The FTIR data (Figure S2b (Supplementary Materials)) displays a strong absorption IR band at $437 \mathrm{~cm}^{-1}$, which is ascribed to vibration $\mathrm{Zn}-\mathrm{O}$ modes $[27,28]$. Other IR bands relate to traces of thermal treatment. At $3470 \mathrm{~cm}^{-1}$, the broad IR band is assigned to the $\mathrm{O}-\mathrm{H}$ stretching mode $(v(\mathrm{OH}))$ of the hydroxyl group of absorbed water. The IR bands observed between 1630 and $860 \mathrm{~cm}^{-1}$ are associated with stretching modes of carbonate group, coming from remains of thermal treatment [29]. Therefore, structural characterization confirms the synthesis of $\mathrm{ZnO}$. Additionally, we carry out a morphological characterization of synthesized $\mathrm{ZnO}$ by FE-SEM (Figure S2c (Supplementary Materials)), which shows nanoparticles' agglomerates with a heterogeneous distribution and irregular forms. The image analysis of the nanoparticles displays the average size to $56 \pm 8 \mathrm{~nm}$ (Figure S2c (Supplementary Materials)). Note that $\mathrm{ZnO}$ is nanoparticles without a defined organization. Specifically, Figure S2d (Supplementary Materials) allows observing clearly and unequivocally the nanometric character of the obtained $\mathrm{ZnO}$. A close study of a particle is shown in Figure S2e (Supplementary Materials). The determined lattice spacing of $\sim 1.630 \AA$ can be attributed to the $\mathrm{ZnO}$ (110) plane according to the JCPDS Card No. 79-0206.

It should be noted that recently we have been evidenced an excellent antimicrobial response of the nanoparticulated $\mathrm{ZnO}$ against multidrug-resistant organisms (MDROs), which strongly depends on the crystalline defects of $\mathrm{ZnO}$ [30]. In the next section, we go a step further and will demonstrate that the high antimicrobial activity can be used for the development of an inorganic composite as a paint preservative for antifungal applications

\subsection{Finding a Potential Technological Application of the ZnO/Clay Composite}

To study the relevant role as a preservative of nanoparticulated $\mathrm{ZnO}$, market available raw materials are used. The selected matrix was modified bentonite clay with the presence of another inorganic preservative as silver. The choice of modified bentonite clay with Ag cations, hereafter Clay, is due to the well-known antibacterial properties of Ag [31,32]. Even, previous studies show the good antibacterial activity of this modified clay against different types of bacteria $[30,33]$. Therefore, it is mandatory to complement the antibacterial activity of Ag cation with a preservative against fungi 
such as $\mathrm{ZnO}$. For a better integration of $\mathrm{ZnO}$ obtained with modified bentonite clay, we pose a dry dispersion of them at room temperature to avoid alteration of the materials [34]. Recently, the dry dispersion method was proposed to obtain hierarchical nanoparticle-microparticle systems with unusual properties by mixing oxides of dissimilar materials [34-38]. These hierarchically-dispersed materials raise additional environmental value since their synthesis is particularly clean. They are prepared by mixing oxides of different materials using a residue-free and solvent-free nanodispersion method that leads to hierarchical nano-microparticle systems [34-38]. More importantly, it has been proven that, after the partial reaction of two oxides, the creation of interfaces at the nano-scale range endows these materials with new properties that range from magnetic or optic to catalytic $[34,35,37,38]$, due to proximity and diffusion phenomena. Consequently, here, the dry dispersion method is taking advantage of the surface energy differences between dissimilar oxide that it attained by shaking the modified clay with $\mathrm{ZnO}$ obtained, and $1 \mathrm{~mm} \mathrm{ZrO}_{2}$ balls in a $60 \mathrm{~cm}^{3}$ nylon container for $5 \mathrm{~min}$ at $50 \mathrm{rpm}$ using a tubular-type mixer.

Different composites $\mathrm{ZnO} / \mathrm{Clay}$ are obtained according to the concentration of nanoparticulated $\mathrm{ZnO}$, from 2 to $60 \mathrm{wt} . \%$. The structural characterization of the composites is carried out by XRD (Figure 1). As discussed above, the XRD pattern of $\mathrm{ZnO}$ obtained matches the hexagonal wurtzite structure ZnO (JCPDS Card No. 36-1451). The XRD pattern of bentonite (Figure S3 (Supplementary Materials)) shows the typical diffraction peaks (JCPDS Card No. 003-0019) and the presence of cristobalite as an impurity (JCPDS Card No. 039-1425). As expected, the XRD pattern of ZnO/Clay composite displays an increase in the intensity of the diffraction peaks relative to $\mathrm{ZnO}$ while the diffraction peaks of clay decrease their intensity accordingly.

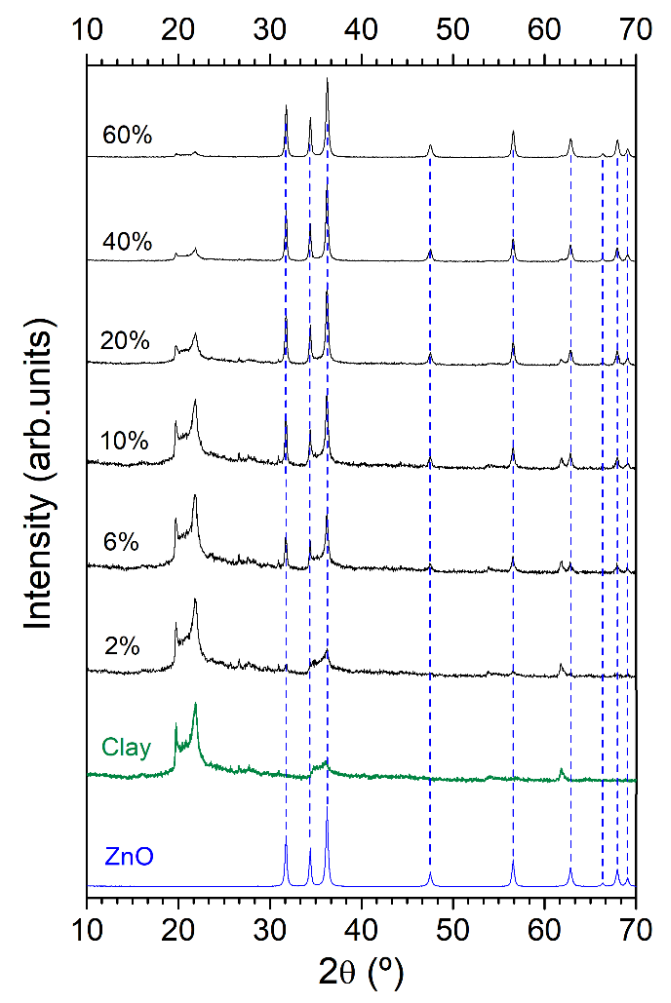

Figure 1. Structural characterization of $\mathrm{ZnO}$ obtained and $\mathrm{ZnO} /$ Clay composites. XRD diffractograms of $\mathrm{ZnO}$, bentonite clay and modified clay with different compositions of $\mathrm{ZnO}$ (from $2 \%$ to $60 \%$ ).

In order to clarify the addition of $\mathrm{ZnO}$ and the dispersion state of $\mathrm{ZnO} /$ Clay composites, a FE-SEM characterization is performed. For this, it is necessary to separately characterize the morphology of each $\mathrm{ZnO} / \mathrm{Clay}$ composite components (that is, the bentonite clay and the nanoparticulated $\mathrm{ZnO}$ ). So, the bentonite clay is composed of layers or compacted plates (Figure S4a (Supplementary 
Materials)). While the morphology of nanoparticulated $\mathrm{ZnO}$ (Figure S4b (Supplementary Materials)) are nanoparticles with sizes of ca. $56 \mathrm{~nm}$. Note that the expected behavior about the dispersion of nanoparticulated $\mathrm{ZnO}$ is a partial coating of clay aggregates, according to the dry dispersion procedure $[34,36,37]$. Figure 2 displays the changes in clay morphology corresponding to the addition of nanoparticulated $\mathrm{ZnO}$. The $2 \mathrm{wt} . \%$ of dispersed $\mathrm{ZnO}$ on clay (Figure 2a) is practically not observed in the micrograph. From $6 \mathrm{wt} . \%$ of $\mathrm{ZnO}$ (Figure $2 \mathrm{~b}$ ), nanoparticles of $\mathrm{ZnO}$ are deposited onto the clay surface. For concentration between $10 \mathrm{wt} . \%$ (Figure 2c) and $20 \mathrm{wt} . \%$ (Figure 2d) of dispersed $\mathrm{ZnO}$, the presence of nanoparticle onto clay surface increases, reaching a coated clay. Figure 2e shows the first appearance of $\mathrm{ZnO}$ agglomerates due to a high concentration of $\mathrm{ZnO}$ nanoparticles. When the concentration of $\mathrm{ZnO}$ increases, the quantity, and size of agglomerates also rise (Figure 2f). Consequently, a dispersion mechanism can be established depending on the deposited material concentration. The clay agglomerates serve like the base of the dispersion of the $\mathrm{ZnO}$ (Figure $2 \mathrm{~g}$ ). At low concentrations of $\mathrm{ZnO}$, from 2 to $10 \mathrm{wt}$ \% (Figure 2g), the distribution of $\mathrm{ZnO}$ is uniform onto the clay surface. Once the surface coating is reached, the agglomeration of $\mathrm{ZnO}$ nanoparticles occurs (Figure 2g).
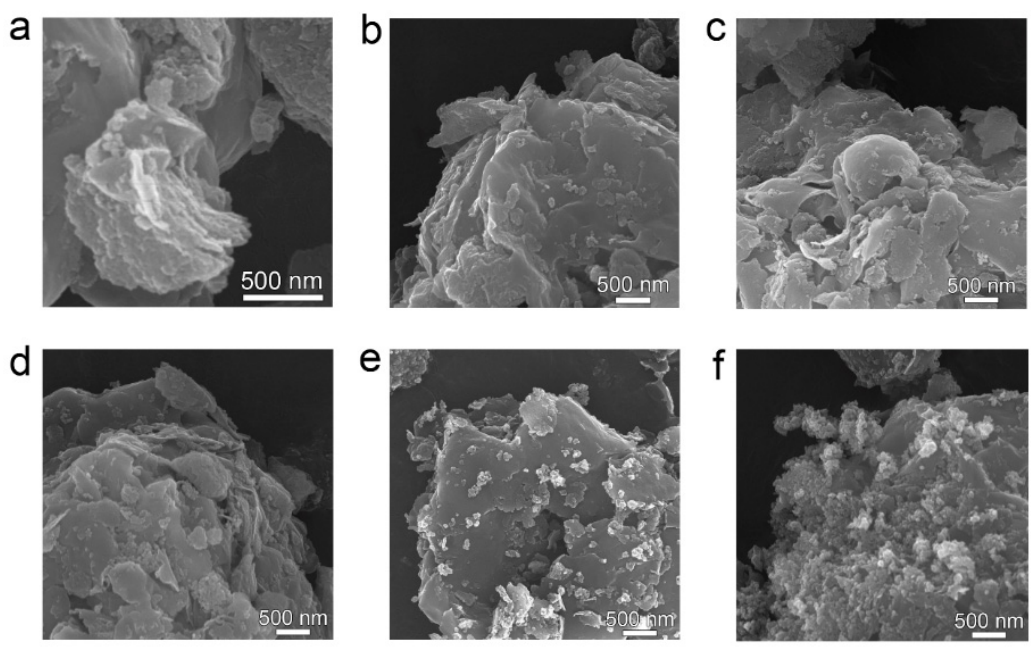

g

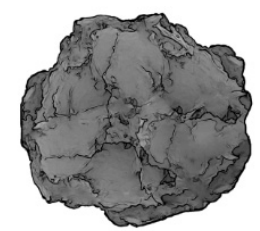

1

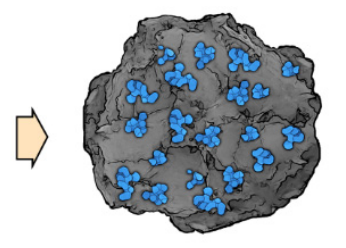

2

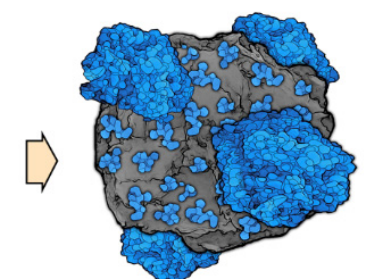

3

Figure 2. Distribution of $\mathrm{ZnO}$ on bentonite modified clay by dry dispersion methodology. Panels (a) to (f) show the micrographs of $\mathrm{ZnO} /$ clay after the incorporation of different $\mathrm{ZnO}$ concentrations- $2 \%$ (a), $6 \%($ b), $10 \%$ (c), $20 \%$ (d), $40 \%$ (e), 60\% (f). Panel (g) shows the steps of composite evolution according to $\mathrm{ZnO}$ concentration: (1) no $\mathrm{ZnO}$ addition, (2) $\mathrm{ZnO}$ concentration from $2 \%$ to $10 \%$, (3) concentration upper than $20 \%$.

The antifungal response of $\mathrm{ZnO} / \mathrm{Clay}$ composites is tested by the Bauer-Kirby disk diffusion assay. The fungus selected for the assay is Aspergillus niger, which is incubated at $37^{\circ} \mathrm{C}$ for three days after $\mathrm{ZnO} /$ Clay addition. As shown in Figure $3 \mathrm{a}, \mathrm{b}$, the presence of nanoparticulated $\mathrm{ZnO}$ improves the antifungal inhibition ratio of the bentonite clay. Evaluating the antifungal evolution as a function of the $\mathrm{ZnO}$ concentration (Figure 3c), an increase in the sporulation inhibition diameter (SID) is observed. Modified bentonite clay with Ag cation has a very low antifungal response (called B). This fact is in accordance with the lack of antifungal activity of Ag that literature reports. By contrast, it has been reported by Monte-Serrano et al. [33] that the use of the modified bentonite clay with Ag cations 
guarantees an effective antibacterial activity. This fact should endow the $\mathrm{ZnO} /$ Clay system of a combined action between Ag-Zn cations, where the Ag cations guarantee the antibacterial activity, while $\mathrm{Zn}$ cations provide the antifungal activity. At low $\mathrm{ZnO}$ concentrations, between 2 to $10 \mathrm{wt} . \%$ (named as C to E), the SID increases exponentially. When $20 \mathrm{wt} . \%$ of $\mathrm{ZnO}$ (F) is reached, the SID behavior changes towards a more moderate improvement. This asymptotic character is maintained for higher $\mathrm{ZnO}$ concentrations as $40 \mathrm{wt} . \%(\mathrm{G})$ and $60 \mathrm{wt} . \%(\mathrm{H})$. Therefore, the relationship between the addition of $\mathrm{ZnO}$ and antifungal activity is not linear. There are two well-differentiated linear regressions whose intersection occurs at $10 \mathrm{wt} . \%$ (E). At concentration below $10 \mathrm{wt} . \%, \mathrm{ZnO}$ nanoparticles are well dispersed onto clay, which coincides with faster efficacy growth of the antifungal activity (see Figure $3 \mathrm{c}$ green zone). When agglomerates appear on clay at concentration upper $10 \mathrm{wt} . \%$, the growth of the antifungal response is reduced (see Figure $3 \mathrm{c}$ red zone). Hence, $\mathrm{ZnO}$ agglomerates onto clay surface are less effective with respect to the uniformly dispersed $\mathrm{ZnO}$. These results prove the importance of both the uniform distribution and an adequate concentration of the $\mathrm{ZnO}$ nanoparticles onto the clay surface for the antifungal activity of composite.
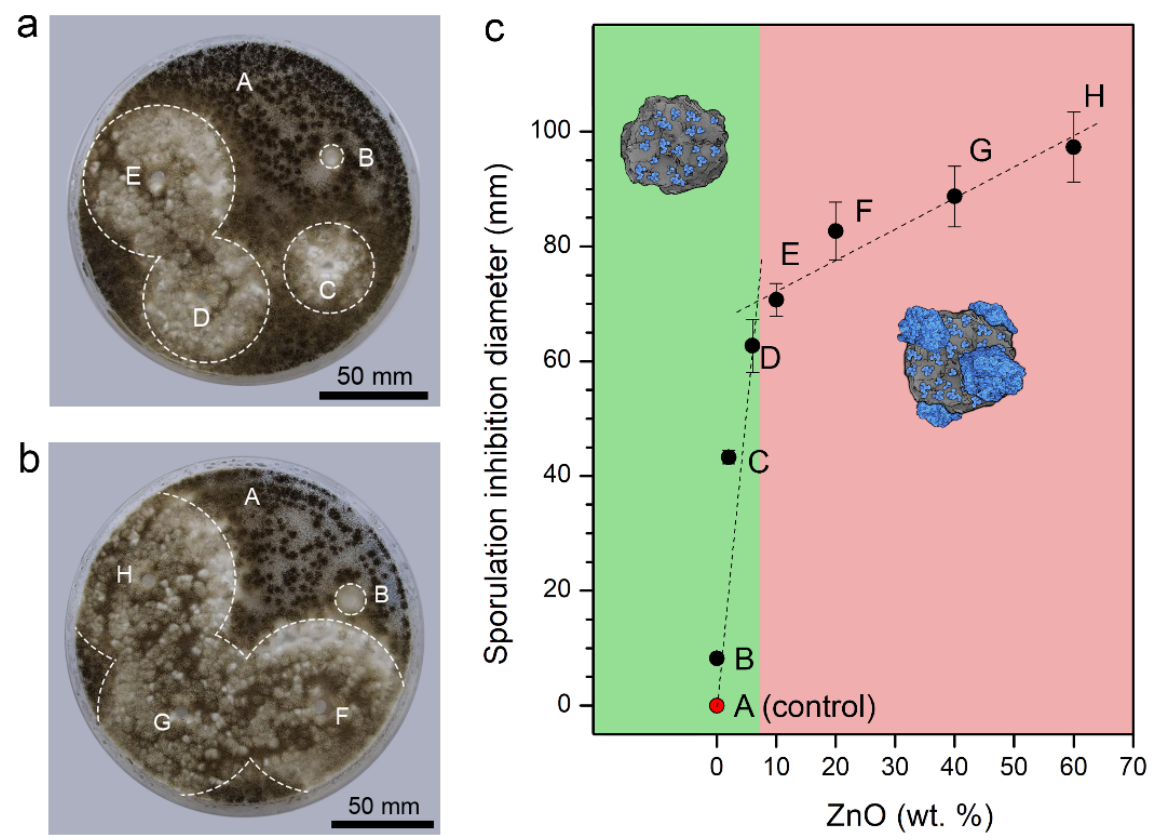

Figure 3. Antifungal activity test of $\mathrm{ZnO} /$ Clay composites against Aspergillus niger. Panels (a) and (b) show photographs of Bauer-Kirby disk diffusion assay for different composition of $\mathrm{ZnO}$ (wt.\%) content in clay: (A) Control, (B) clay, (C) 2\%, (D) 6\%, (E) 10\%, (F) 20\%, (G) 40\%, (H) 60\%. Panel (c) shows sporulation inhibition diameter data mean values and standard errors of a $0.5 \mathrm{wt} . \%$ concentration of $\mathrm{ZnO} /$ Clay. The effectiveness zone is represented in green and one of less effectiveness is colored in red. Each data represents an average of triplicate measurements.

According to the promising results against fungi, the antifungal response of $\mathrm{ZnO} / \mathrm{Clay}$ composite is tested in a waterborne paint matrix. The same method and conditions as in the previous antifungal test are used. The experiments are collected in Figure 4a and Figure S5 (Supplementary Materials). The waterborne paint was modified with a concentration of $0.5 \mathrm{wt} . \%$ of $\mathrm{ZnO} /$ Clay composite with a $\mathrm{ZnO}$ content of $10 \mathrm{wt} . \%$ (i.e., $0.05 \mathrm{wt} . \%$ of $\mathrm{ZnO}$ nanoparticles). The very low concentration is selected due to the adequate compromise between $\mathrm{ZnO}$ dispersion and antifungal response. Two conditions of the waterborne paint, fresh and dry, are taken into account. As shown in Figure 4a, the fresh paint without the presence of $\mathrm{ZnO} / \mathrm{Clay}$ composite, as control, displays a poor inhibition diameter. The fresh paint with $\mathrm{ZnO} / \mathrm{Clay}$ composite incorporated shows a SID greater than control. By contrast, the dry paint practically does not have sporulation inhibition. The dry paint with $\mathrm{ZnO} / \mathrm{Clay}$ composite added improves considerably the inhibition of fungi growth. Figure $4 \mathrm{~b}$ collects the sporulation inhibition 
diameter (SID) observed in the Bauer-Kirby disk diffusion assay. The fresh paint SID (I) may be related to the paint composition such as additives, fillers, pigments, solvents, and resins. Once the $\mathrm{ZnO} /$ Clay composite is incorporated into the paint (II), the action diameter against fungi growth increases. This increase in antifungal activity indicates synergy between fresh paint and $\mathrm{ZnO} / \mathrm{Clay}$ composite. When the paint is dry, the SID difference between control (III) and modified paint (IV) increases significantly. Therefore, the antifungal response of waterborne paint without modification is due to the volatile compounds of its formulation. It should be highlighted that the $\mathrm{ZnO} / \mathrm{Clay}$ composite keeps the good antifungal response both for fresh paint and for dry paint. In both cases, fresh and dry paint with $\mathrm{ZnO} /$ Clay composite improve the antifungal response.
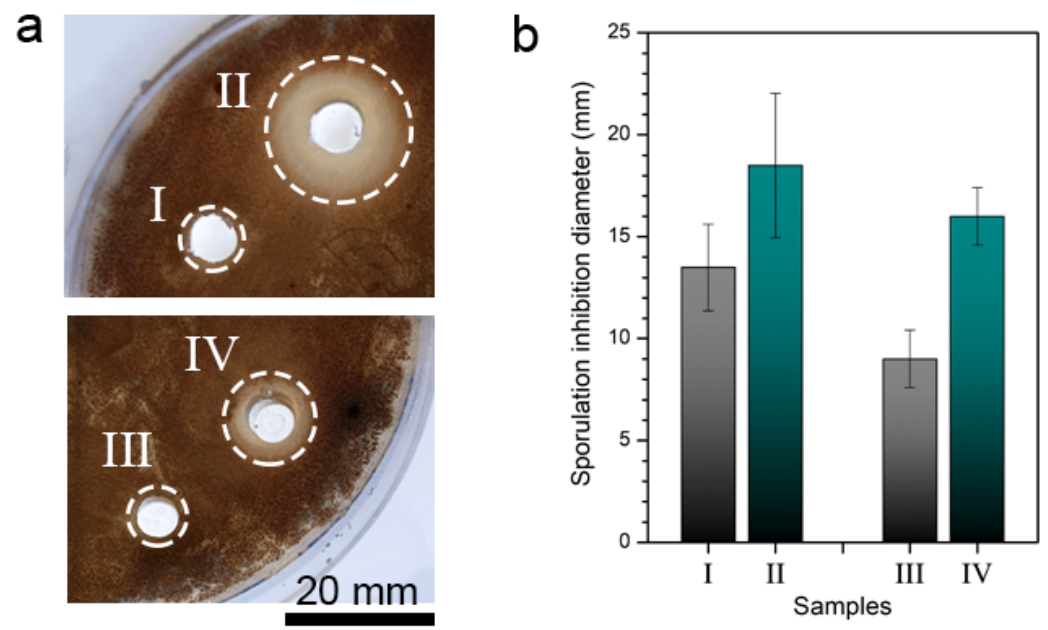

Figure 4. Antifungal activity test of waterborne paint with $0.5 \%$ of $\mathrm{ZnO} /$ Clay composite. (a) Bauer-Kirby disk diffusion assay of fresh paint (I), fresh paint with ZnO/Clay (II), dry paint (III) and dry paint with $\mathrm{ZnO} /$ Clay (IV). Panel (b) shows sporulation inhibition diameter data of (I) fresh paint, (II) fresh paint with $\mathrm{ZnO} / \mathrm{Clay}$, (III) dry paint and (IV) dry paint with $\mathrm{ZnO} / \mathrm{Clay}$. The mean and standard deviation (s.d.) from the three experiments is shown.

The antifungal activity observed in $\mathrm{ZnO} /$ Clay composite (Figure 3) is maintained for its application in paints (Figure 4). The excellent antifungal activity of fresh and dry paint points to the availability of $\mathrm{ZnO}$ in the matrix thanks to the dry dispersion method. The $\mathrm{ZnO}$ concentration added in the finished product for antifungal response is $0.05 \mathrm{wt} . \%$, a value well below other antifungals such as zinc pyrithione, typical addition 2.0\% [7]. At a very low concentration of $\mathrm{ZnO} / \mathrm{Clay}(0.5 \mathrm{wt} . \%)$, the paint does not significantly increase the cost production and improves considerably the antifungal response.

\section{Conclusions}

In summary, we are able to achieve a paint preservative based on $\mathrm{ZnO}$ nanoparticles and modified clay. The $\mathrm{ZnO} / \mathrm{Clay}$ composite formation by a dry dispersion allows obtaining a controlled and uniform surface coating of $\mathrm{ZnO}$. The addition of $\mathrm{ZnO}$ nanoparticles improves the antifungal properties of modified clay against a common fungus, $A$. niger. The use of $\mathrm{ZnO} /$ Clay composite as a fungicide is in accordance with the established guidelines to find alternatives from natural resources. To evaluate the effectiveness of $\mathrm{ZnO} / \mathrm{Clay}$ composite as a preservative, we introduce the composite in a waterborne paint matrix. The antifungal test shows the improved response in both fresh and dry paint with the $\mathrm{ZnO} /$ Clay composite addition. It is worth noting that the combination of modified clay and $\mathrm{ZnO}$ nanoparticles in one preservative composite product and at a low concentration, such as $0.5 \mathrm{wt} . \%$, optimizes the cost production and the amount of material required, besides tolerating the incorporation in other matrixes. Therefore, this composite is a strong candidate for a huge range of applications such as coatings in outdoor environments, the formation of antifungal textile fibers or integration into polymers. 
Supplementary Materials: The following are available online at http://www.mdpi.com/2076-3417/10/4/1322/s1, Supplementary Information 1. Size modification process of the micrometric ZnO via chemical route; Supplementary Information 2. Structural and morphological characterization of the nanoparticulated ZnO; Supplementary Information 3. XRD pattern of modified bentonite clay; Supplementary Information 4. Morphological characterization of inorganic composite precursors; and Supplementary Information 5. Replicas of Bauer-Kirby disk diffusion assay in the paint matrix.

Author Contributions: E.d.L.-G., and F.R.-M. conceived the idea and designed the experiments. E.d.L.-G. prepared the samples. E.d.L.-G., and F.R.-M. performed the XRD and FE-SEM characterization. L.P. performed the HR-TEM characterization. J.M. and E.d.L.-G. performed the antifungal activity test. Data processing was carried out by E.d.L.-G., J.F.F., J.M., and F.R.-M. All the authors contributed to the discussion of the results E.d.L.-G. and F.R.-M. wrote the manuscript with input from J.F.F. The work was supervised by J.F.F. and F.R.-M. All authors have read and agreed to the published version of the manuscript.

Acknowledgments: This work was supported by the Spanish Ministry of Economy and Competitiveness (MINECO) under the projects MAT2017-86450-C4-1-R, and the Spanish National Research Council (CSIC) under the project NANOMIND CSIC 201560E068. F. Rubio-Marcos is indebted to MINECO for a "Ramon y Cajal" contract (ref: RyC-2015-18626), which is co-financed by the European Social Fund.

Conflicts of Interest: The authors declare the following competing financial interest(s): J.M. is an employee of Encapsulae, S.L.

\section{References}

1. Roberts, J.R.; Reigart, J.R. Fungicides, Recognition Management Pesticide Poisonings, 6th ed.; U.S. Environmental Protection Agency: Washington, WA, USA, 2013; pp. 143-160. Available online: https://www.epa.gov/sites/ production/files/documents/rmpp_6thed_ch16_fungicides.pdf (accessed on 18 October 2018).

2. Rouabhi, R. Introduction and toxicology of fungicide. In Fungicides; INTECH Open Access Publisher: Guangdong, China, 2010; pp. 363-382. [CrossRef]

3. Ballantyne, B. Pesticide toxicology and international regulation. In Pesticide Toxicology International Regulation; Marrs, T.C., Ballantyne, B., Eds.; John Wiley \& Sons, Ltd.: Chichester, UK, 2003; pp. 193-303. [CrossRef]

4. Gupta, P.K. Toxicity of Fungicides. In Veterinary Toxicology Basic Clinical Principles, 3rd ed.; Elsevier Inc.: Amsterdam, The Netherlands, 2018; pp. 569-580. [CrossRef]

5. Thomas, K.V.; Brooks, S. The environmental fate and effects of antifouling paint biocides. Biofouling 2010, 26, 73-88. [CrossRef]

6. Windler, L.; Height, M.; Nowack, B. Comparative evaluation of antimicrobials for textile applications. Environ. Int. 2013, 53, 62-73. [CrossRef] [PubMed]

7. Bernauer, U.; Chaudhry, Q.; Coenraads, P.-J.; Degen, G.; Dusinska, M.; Lilienblum, W.; Luch, A.; Nielsen, E.; Platzek, T.; Rastogi, S.C.; et al. Opinion on Zinc Pyrithione Colipa $n^{\circ}$ P81; Scientific Committee on Consumer Safety: Brussels, Belgium, 2013.

8. Amara, I.; Miled, W.; Ben Slama, R.; Ladhari, N. Antifouling processes and toxicity effects of antifouling paints on marine environment. A review. Environ. Toxicol. Pharmacol. 2018, 57, 115-130. [CrossRef] [PubMed]

9. Bao, V.W.W.; Leung, K.M.Y.; Qiu, J.-W.; Lam, M.H.W. Acute toxicities of five commonly used antifouling booster biocides to selected subtropical and cosmopolitan marine species. Mar. Pollut. Bull. 2011, 62, 1147-1151. [CrossRef] [PubMed]

10. Guthery, E.; Seal, L.A.; Anderson, E.L. Zinc pyrithione in alcohol-based products for skin antisepsis: Persistence of antimicrobial effects. Am. J. Infect. Control. 2005, 33, 15-22. [CrossRef] [PubMed]

11. Lamore, S.D.; Cabello, C.M.; Wondrak, G.T. The topical antimicrobial zinc pyrithione is a heat shock response inducer that causes DNA damage and PARP-dependent energy crisis in human skin cells. Cell Stress Chaperones 2010, 15, 309-322. [CrossRef]

12. Yamaguchi, Y.; Sakkas, V.A.; Albanis, T.; Sugasawa, S.; Shibata, K. Aqueous phototransformation of zinc pyrithione. J. Chromatogr. A 2007, 1144, 175-182. [CrossRef]

13. Brayner, R.; Ferrari-Iliou, R.; Brivois, N.; Djediat, S.; Benedetti, M.F.; Fiévet, F. Toxicological impact studies based on Escherichia coli bacteria in ultrafine $\mathrm{ZnO}$ nanoparticles colloidal medium. Nano Lett. 2006, 6, 866-870. [CrossRef]

14. Jones, N.; Ray, B.; Ranjit, K.T.; Manna, A.C. Antibacterial activity of ZnO nanoparticle suspensions on a broad spectrum of microorganisms. FEMS Microbiol. Lett. 2008, 279, 71-76. [CrossRef] [PubMed] 
15. Li, M.; Zhu, L.; Lin, D. Toxicity of ZnO nanoparticles to escherichia coli: Mechanism and the influence of medium components. Environ. Sci. Technol. 2011, 45, 1977-1983. [CrossRef]

16. He, L.; Liu, Y.; Mustapha, A.; Lin, M. Antifungal activity of zinc oxide nanoparticles against botrytis cinerea and penicillium expansum. Microbiol. Res. 2011, 166, 207-215. [CrossRef] [PubMed]

17. Sharma, D.; Rajput, J.; Kaith, B.S.; Kaur, M.; Sharma, S. Synthesis of ZnO nanoparticles and study of their antibacterial and antifungal properties. Thin Solid Films 2010, 519, 1224-1229. [CrossRef]

18. Lipovsky, A.; Nitzan, Y.; Gedanken, A.; Lubart, R. Antifungal activity of ZnO nanoparticles-The role of ROS mediated cell injury. Nanotechnology 2011, 22, 105101. [CrossRef] [PubMed]

19. De Lucas-Gil, E.; Leret, P.; Monte-Serrano, M.; Reinosa, J.J.; Enríquez, E.; Del Campo, A.; Cañete, M.; Menéndez, J.; Fernández, J.F.; Rubio-Marcos, F. ZnO nanoporous spheres with broad-spectrum antimicrobial activity by physicochemical interactions. ACS Appl. Nano Mater. 2018, 1, 3214-3225. [CrossRef]

20. De Lucas-Gil, E.; Reinosa, J.J.; Neuhaus, K.; Vera-Londono, L.; Martín-González, M.; Fernández, J.F.; Rubio-Marcos, F. Exploring New mechanisms for effective antimicrobial materials: Electric contact-killing based on multiple schottky barriers. ACS Appl. Mater. Interfaces 2017, 9, 26219-26225. [CrossRef] [PubMed]

21. De Lucas-Gil, E.; Fernández, J.F.; Rubio-Marcos, F. One more step against nanotoxicity: Hierarchical particles designed to antifungal properties. Mater. Des. 2017, 34, 188-195. [CrossRef]

22. Yamamoto, O. Influence of particle size on the antibacterial activity of zinc oxide. Int. J. Inorg. Mater. 2001, 3, 643-646. [CrossRef]

23. Padmavathy, N.; Vijayaraghavan, R. Enhanced bioactivity of ZnO nanoparticles-An antimicrobial study. Sci. Technol. Adv. Mater. 2008, 9, 035004. [CrossRef]

24. Raghupathi, K.R.; Koodali, R.T.; Manna, A.C. Size-dependent bacterial growth inhibition and mechanism of antibacterial activity of zinc oxide nanoparticles. Langmuir 2011, 27, 4020-4028. [CrossRef]

25. Sun, Q.; Li, J.; Le, T. Zinc oxide nanoparticle as a novel class of antifungal agents: Current advances and future perspectives. J. Agric. Food Chem. 2018, 66, 11209-11220. [CrossRef]

26. Wang, M.; Zhao, B.; Xu, S.; Lin, L.; Liu, S.; He, D. Synthesis of hierarchically structured ZnO nanomaterials via a supercritical assisted solvothermal process. Chem. Commun. 2014, 50, 930-932. [CrossRef] [PubMed]

27. Andrés-Vergés, M.; Serna, C.J. Morphological characterization of ZnO powders by X-ray and IR spectroscopy. J. Mater. Sci. Lett. 1988, 7, 970-972. [CrossRef]

28. Vergés, M.A.; Mifsud, A.; Serna, C.J. Formation of rod-like zinc oxide microcrystals in homogeneous solutions. J. Chem. Soc. Faraday Trans. 1990, 86, 959-963. [CrossRef]

29. Nakamoto, K. Infrared and Raman Spectra of Inorganic and Coordination Compounds, 6th ed.; John Wiley \& Sons, Inc.: Hoboken, NJ, USA, 2008. [CrossRef]

30. De Lucas-Gil, E.; Del Campo, A.; Pascual, L.; Monte-Serrano, M.; Menéndez, J.; Fernández, J.F.; Rubio-Marcos, F. The fight against multidrug-resistant organisms: The role of $\mathrm{ZnO}$ crystalline defects. Mater. Sci. Eng. C 2019, 99, 575-581. [CrossRef] [PubMed]

31. Möhler, J.S.; Sim, W.; Blaskovich, M.A.T.; Cooper, M.A.; Ziora, Z.M. Silver bullets: A new lustre on an old antimicrobial agent. Biotechnol. Adv. 2018, 36, 1391-1411. [CrossRef]

32. Agnihotri, S.; Mukherji, S.; Mukherji, S. Size-controlled silver nanoparticles synthesized over the range 5-100 nm using the same protocol and their antibacterial efficacy. RSC Adv. 2014, 4, 3974-3983. [CrossRef]

33. Monte-Serrano, M.; Fernandez-Saiz, P.; Ortí-Lucas, R.M. Effective antimicrobial coatings containing silver-based nanoclays and zinc pyrithione. J. Microb. Biochem. Technol. 2015, 7. [CrossRef]

34. Rubio-Marcos, F.; Calvino-Casilda, V.; Bañares, M.A.; Fernandez, J.F. Novel hierarchical $\mathrm{Co}_{3} \mathrm{O}_{4} / \mathrm{ZnO}$ mixtures by dry nanodispersion and their catalytic application in the carbonylation of glycerol. J. Catal. 2010, 275, 288-293. [CrossRef]

35. Rubio-Marcos, F.; Manzano, C.V.; Reinosa, J.J.; Romero, J.J.; Marchet, P.; Martín-González, M.S.; Fernández, J.F. Mechanism of $\mathrm{Ni}_{1-\mathrm{x}} \mathrm{Zn}_{\mathrm{x}} \mathrm{O}$ formation by thermal treatments on $\mathrm{NiO}$ nanoparticles dispersed over $\mathrm{ZnO}$. J. Phys. Chem. C 2011, 115, 13577-13583. [CrossRef]

36. De Lucas-Gil, E.; Rubio-Marcos, F.; Leret, P.; Motos-Pérez, B.; Monte-Serrano, M.; Menéndez, J.; Fernández, J.F. Opening a new gate to glass preservative with long-lasting antimicrobial activity as replacement of parabens. ACS Sustain. Chem. Eng. 2017, 5, 294-302. [CrossRef] 
37. Martín-González, M.S.; García, M.A.; Lorite, I.; Costa-Krämer, J.L.; Rubio-Marcos, F.; Carmona, N.; Fernández, J.F. A solid-state electrochemical reaction as the origin of magnetism at oxide nanoparticle interfaces. J. Electrochem. Soc. 2010, 157, E31-E35. [CrossRef]

38. Calvino-Casilda, V.; Mul, G.; Fernández, J.F.; Rubio-Marcos, F.; Bañares, M.A. Monitoring the catalytic synthesis of glycerol carbonate by real-time attenuated total reflection FTIR spectroscopy. Appl. Catal. A Gen. 2011, 409-410, 106-112. [CrossRef] 